\title{
Experimental Study on Rock Mechanics Parameters-A Case of the Sand Conglomerate Reservoir in M2 Well Area
}

\author{
Shi Shanzhi ${ }^{1}$ Zhao Chaoneng ${ }^{2}$ Liu Hai $^{1}$ Ding Kun $^{1}$ Li Jie ${ }^{1}$ Chen Jin $^{1}$ Chen Ning $^{1}$ Ma Junxiu ${ }^{1}$ Song Pengju ${ }^{3}$ \\ ${ }^{1}$ Research Institute of Petroleum Engineering of PetroChina Xinjiang Oilfield Company, Karamay, 834000 \\ ${ }^{2}$ Southwest Petroleum University, school of oil and gas engineering, Chendu, 610500 \\ ${ }^{3}$ PetroChina Tarim Oilfield Company, Oil and Gas Engineering Research Institute, Korla, 841000
}

\begin{abstract}
This paper presents the acoustic characteristics tested on 20 groups of cores (20 vertical samples and 60 horizontal samples) from the sand conglomerate reservoir in Baikouquan and lower Wuerhe Formation (two wells in the M2 well area). The average values of dynamic modulus of elasticity and Poisson's ratio of rocks from Baikouquan Formation are $32.1 \mathrm{GPa}$ and 0.2055 respectively, and those of lower Wuerhe Formation are $28.4 \mathrm{GPa}$ and 0.2425 respectively. The three axis rock mechanics test device is used to test the stress-strain curves of the corresponding rock samples. The sand-conglomerate samples in this area generally have good brittleness characteristics; the static modulus of elasticity and Poisson's ratio of the corresponding rock samples are $13.7 \mathrm{GPa}$ and 0.2858 respectively, and those of rocks from lower Wuerhe Formation are 14.9GPa and 0.2565 , respectively. In general, there is a good correlation between P\& $\mathrm{S}$ wave velocity, and poor correlation in the dynamic and static mechanical parameters.
\end{abstract}

\section{Introduction}

The development test of sand-conglomerate tight oil reservoir in Mahu depression of Junggar Basin has achieved good results ${ }^{[1]}$, but many unknowns need to be further studied. In view of the important role of rock mechanics parameters in drilling engineering and fracturing engineering ${ }^{[2-3]}$, and different acoustic and mechanical characteristics in different regions and lithologic reservoirs ${ }^{[4]}$, so it arouses highly attention in the industry. At present, the main methods to obtain rock mechanics parameters are indoor single or three axis stress test

method ${ }^{[5-6]}$, acoustic characteristic calculation method ${ }^{[7-8]}$ or log interpretation method ${ }^{[9-11]}$. The static modulus of elasticity and static Poisson's ratio obtained by the core test are better to reflect the rock deformation, and have been widely used in the field of petroleum engineering ${ }^{[12-14]}$. The logging interpretation method is essentially a method of calculating the acoustic characteristics of dynamic modulus of elasticity and dynamic Poisson's ratio according to $\mathrm{P} \& \mathrm{~S}$ wave logging data, while it needs to be adjusted from the dynamic value to the static one for application in the engineering practice $^{[15]}$.

There are 20 groups of $\phi 25,80$ rock samples (1 vertical sample and 3 horizontal sample every $45^{\circ}$ in each group) from sand conglomerate reservoir in Baikouquan and lower Wuerhe Formation (M20001 and M21008 wells). First, P\& S wave velocity of rock samples is tested by experiments to calculate the dynamic modulus of elasticity and dynamic Poisson's ratio, and then the static mechanics parameters under the triaxial condition are tested. The characteristics of static and dynamic mechanics parameters and transformation relation thereof are established to comprehensively and effectively evaluate the characteristics of rock mechanics parameters, which provide technical support for the oil exploration and development engineering in this area.

\section{$2 \mathrm{P} \& \mathrm{~S}$ wave velocity testing and dynamic mechanics parameters}

\subsection{Experiment on P\& S wave velocity of rocks}

The SCMS-E high temperature and pressure core multi-parameter tester is used to measure $\mathrm{P} \& \mathrm{~S}$ velocity of rocks based on the transmission principle. The core specimen is installed into the core clamp. The two ends of the specimen are connected with the acoustic wave generator and the acoustic oscilloscope respectively. The acoustic generator is excited 1 times, corresponding to 1 set of waveforms collected by the acoustic oscilloscope. By measuring the arrival time of the head wave of $P \& S$ wave, the propagation speed of $\mathrm{P} \& \mathrm{~S}$ wave in the core specimen will be calculated.

The formula for calculating the $\mathrm{P} \& \mathrm{~S}$ wave velocity is as follows:

$$
V_{p}=\frac{L}{\Delta t_{p}-\Delta t_{p_{0}}} \times 10000
$$




$$
V_{s}=\frac{L}{\Delta t_{s}-\Delta t_{s_{0}}} \times 10000
$$

Where

$\mathrm{Vp}, \mathrm{Vs}-\mathrm{P} \& \mathrm{~S}$ wave velocity, $\mathrm{m} / \mathrm{s}$;

$\mathrm{L}$-Sample length, $\mathrm{cm}$;

$\Delta \mathrm{t}_{\mathrm{p}}, \Delta \mathrm{t}_{\mathrm{s}}$-Travel time of testing P\& S wave, $\mu \mathrm{s}$;

$\triangle \mathrm{t}_{\mathrm{p} 0} 、 \triangle \mathrm{t}_{\mathrm{s} 0}$-Time in probes for $\mathrm{P} \& \mathrm{~S}$ wave, $\mu \mathrm{s}$.

The experiment was performed to measure $\mathrm{P} \& \mathrm{~S}$ wave of 80 samples from the two wells, an example of the measured wave form is shown in Fig.1.

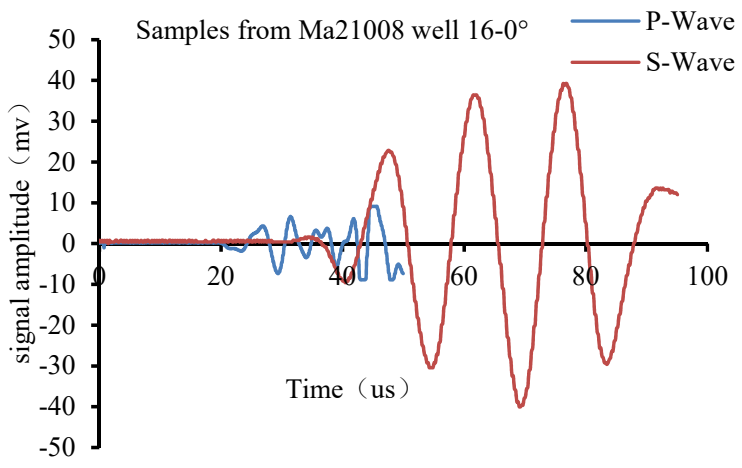

(a) $\operatorname{Ma} 21008\left(0^{\circ}\right.$ sample $)$

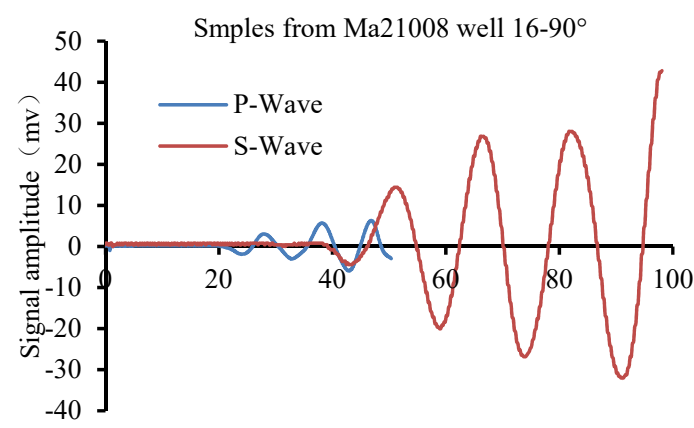

Time (us)

(b) Ma21008 (90 sample)

Fig.1 Graphs on $\mathrm{P} \& \mathrm{~S}$ wave form of $\mathrm{P}_{2} \mathrm{~W}_{2}{ }^{2-2}$ cores from M21008 well

The measured results of $\mathrm{P} \& \mathrm{~S}$ wave velocity of rocks from M20001 and M21008 wells are shown in Fig.2. There is a good correlation between $\mathrm{P} \& \mathrm{~S}$ wave velocity of sand conglomerate in M2 well area but difference in the correlation for the 2 wells.

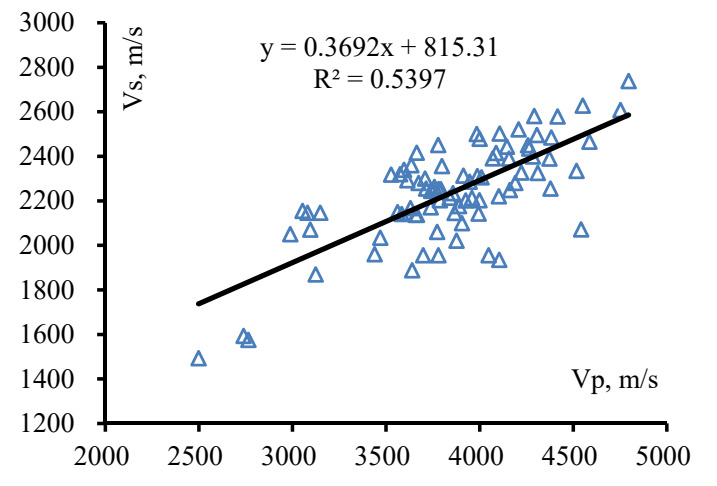

(a) Complete experimental data

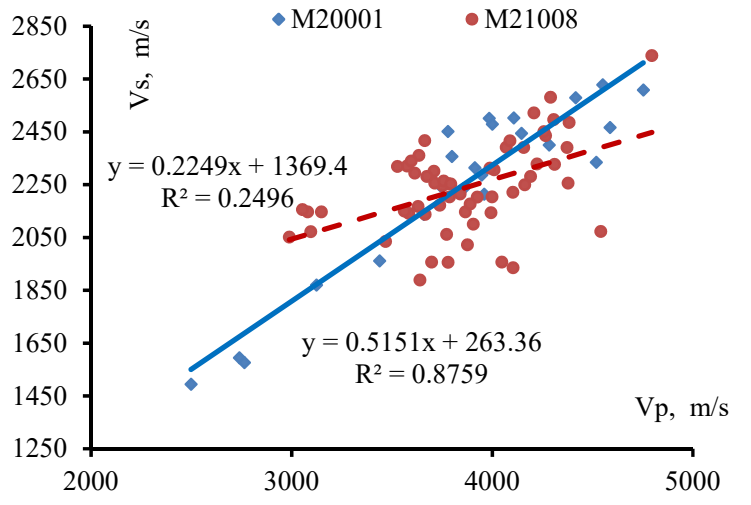

(b) Data as per well

Fig.2 Correlation of P\& S wave for M2 well area

\subsection{Analysis on dynamic mechanics parameters of rocks}

Assuming that the rock is a homogeneous and isotropic linear elastic body, the formula for calculating the dynamic mechanical parameters of rock samples based on the $\mathrm{P} \& \mathrm{~S}$ wave velocity of rocks is as follows $[6,7]$

$$
E=\frac{\rho V_{s}^{2}\left(3 V_{p}^{2}-4 V_{s}^{2}\right)}{V_{p}^{2}-V_{s}^{2}} \quad \mu=\frac{V_{p}^{2}-2 V_{s}^{2}}{2\left(V_{p}^{2}-V_{s}^{2}\right)}
$$

where:

$\rho$ - bulk density of rocks, $\mathrm{kg} / \mathrm{m}^{3}$;

$E$-Dynamic modulus of elasticity of rocks, Pa;

$\mu$-Poisson's ratio of rocks, dimensionless.

The calculated dynamic modulus of elasticity and dynamic Poisson's ratio are shown in Fig.3. The dynamic modulus of elasticity dynamic and Poisson's ratio of rocks from Baikouquan Formation are respectively 23152 42242MPa (mean $32146 \mathrm{MPa}$ ) and $0.077 \sim 0.318$ (mean 0.2055), while the dynamic modulus of elasticity dynamic and Poisson's ratio of rocks from lower Wuerhe Formation are 12728 42562MPa (mean28401MPa) and $0.095 \sim 0.357$ (mean0.2425). 


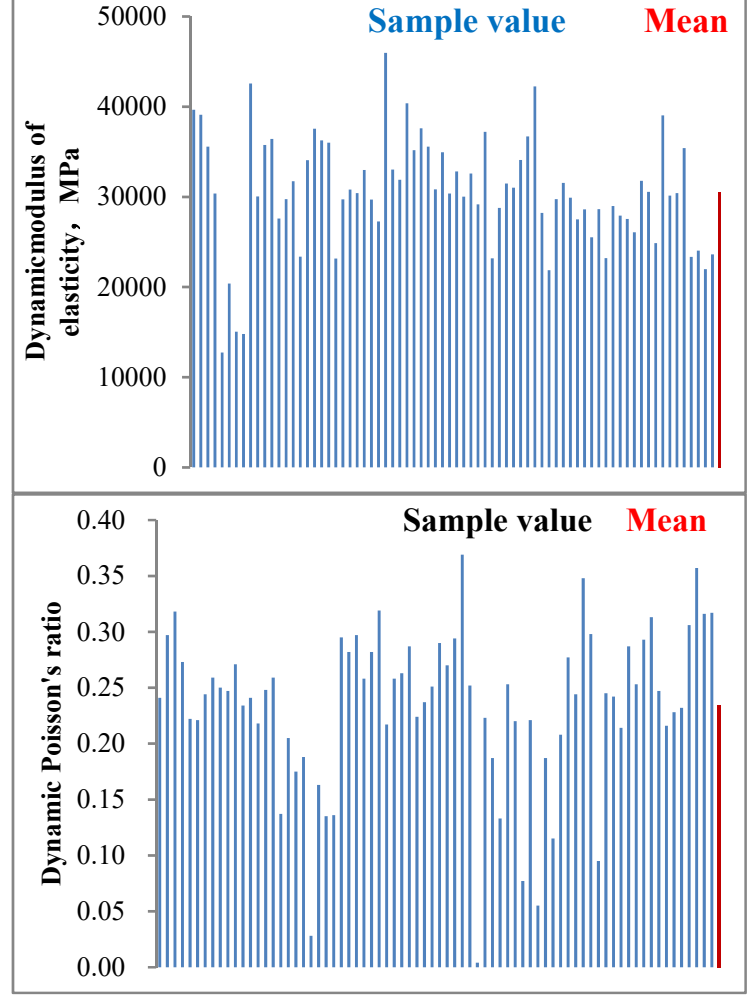

Fig.3 Test results of dynamic mechanical parameters of rock samples from M2 well area

\section{Experimental test on static mechanics parameters of rocks}

The high temperature \&pressure triaxial rock mechanics test device was used to measure static mechanics parameters of 80 rock samples as per the national standard ${ }^{[5]}$. The experimental curves of some rock samples were shown in Fig.4 and 5. Judging from the curve, the sand conglomerate in M2 well area is generally characterized by good brittleness. The experimental test results are given in Fig. 6 with the static modulus of elasticity $7885 \sim 16770 \mathrm{MPa}$ (average $13745 \mathrm{MPa})$ and static Poisson's ratio 0.193 0.443(average 0.2858) of rocks from Baikouquan Formation, and the static modulus of elasticity $8601 \sim 21042 \mathrm{MPa}$ (average 14884MPa) and static Poisson's ratio 0.111 0.396 (average 0.2565) of rocks from low Wuerhe Formation

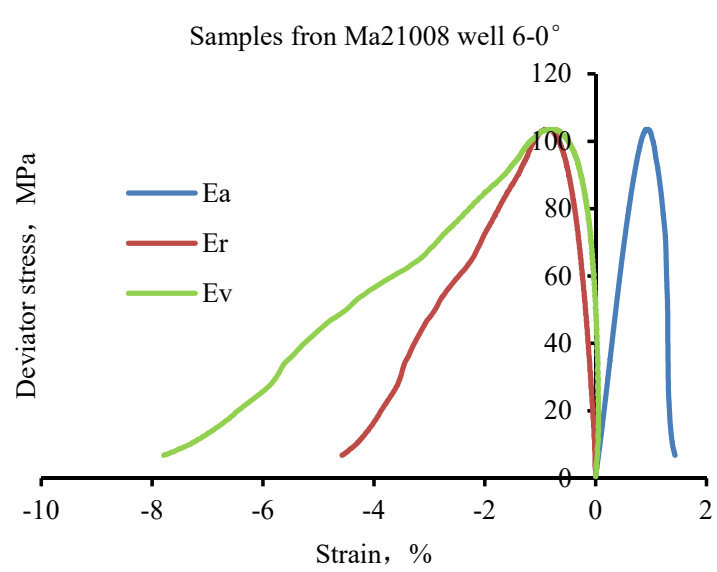

(A)

Samples from Ma21008 well 6-45

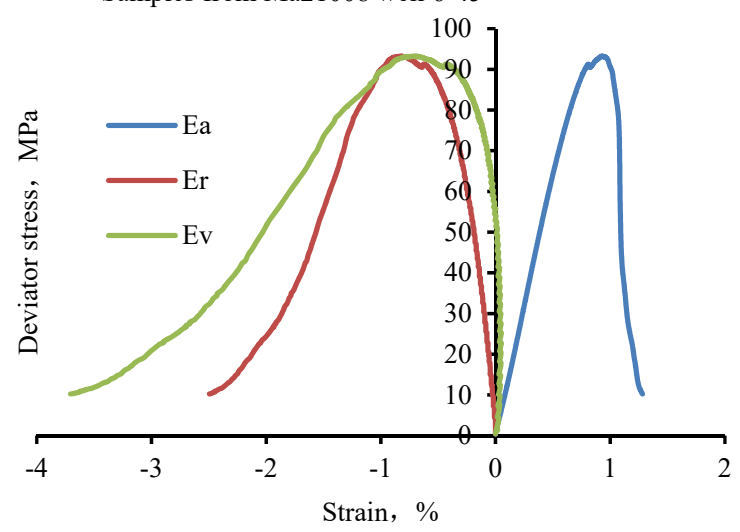

(B)

Fig.4 Stress-strain curve from the triaxial mechanics test on $8 \#$ core samples from M21008 well

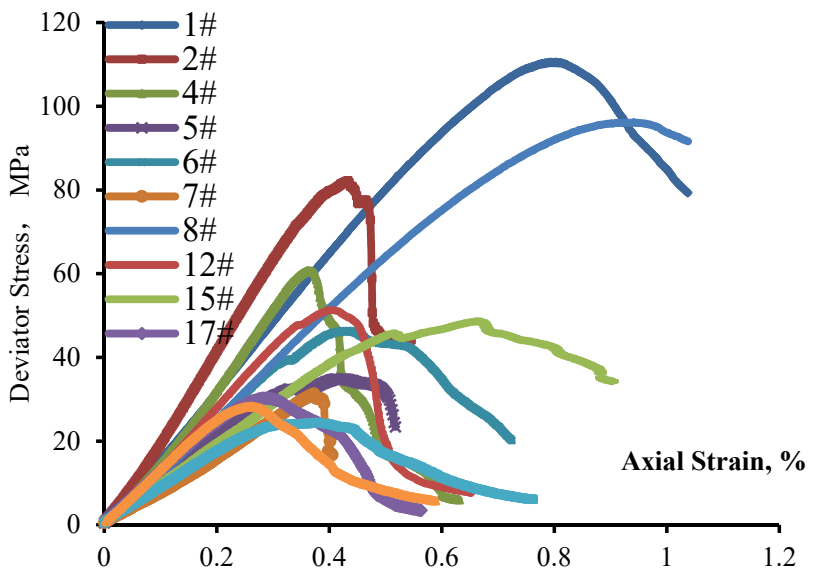

Fig.5 Stress-strain curve of rock samples from M2 well area (Partial) 


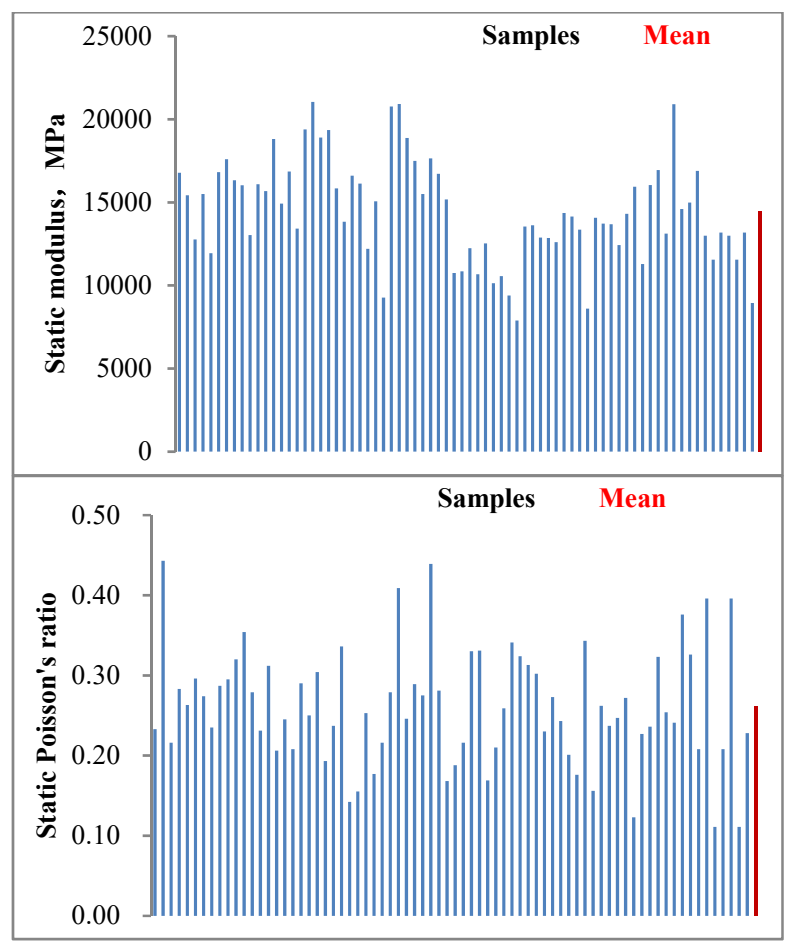

Fig.6 Experimental results of static mechanics parameters of rocks from $\mathrm{M} 2$ well area

\section{Relations between dynamic and static mechanics parameters of rocks}

The dynamic elastic parameters of rocks are calculated by using $\mathrm{P} \& \mathrm{~S}$ wave velocity of rock samples based on static mechanics parameters of rocks obtained by the triaxial experiment. The relationship between dynamic and static Young's modulus of elasticity and Poisson's ratio of rocks from M2 well area and stratification is established as shown in Fig.7, and the conversion relationship is shown in Fig.8.

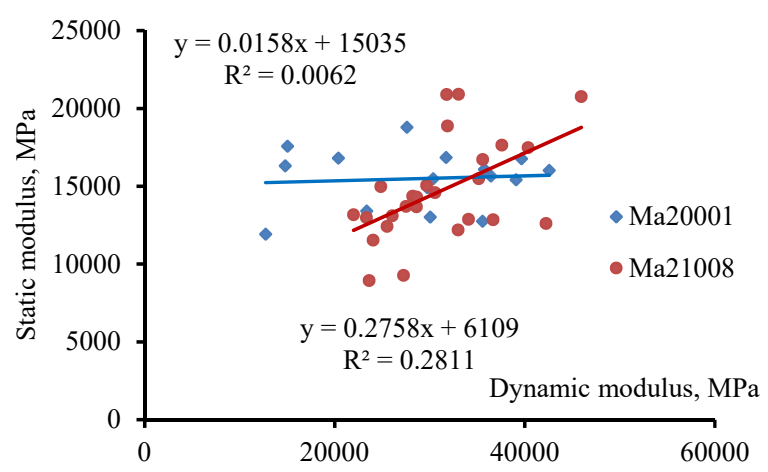

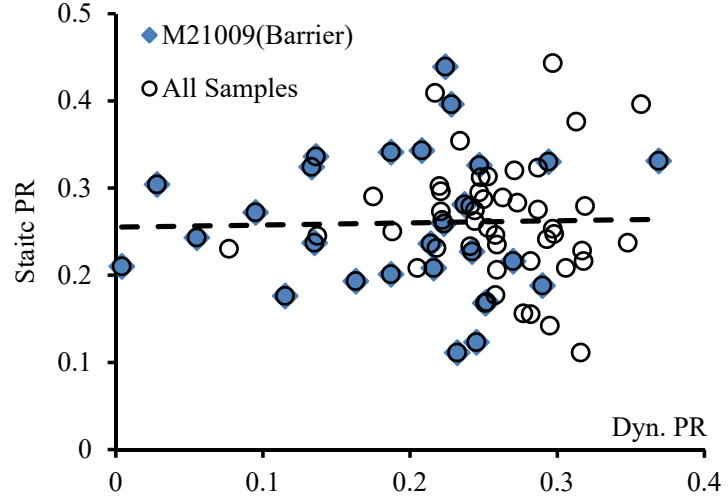

Fig.7 The conversion relationship between dynamic and static parameters of rocks from M2 well area
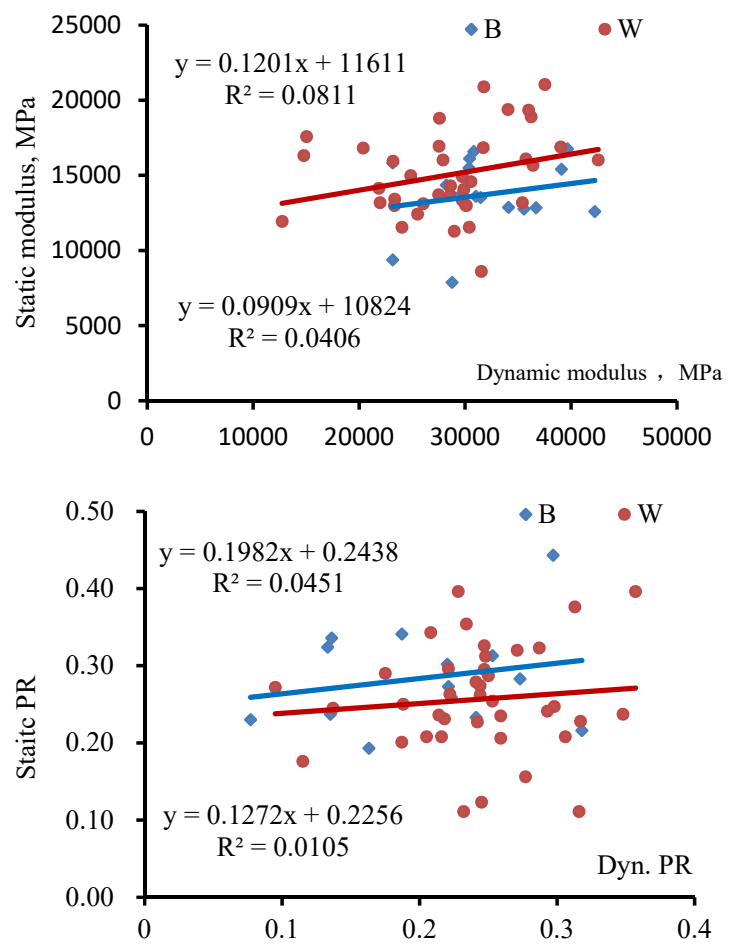

Fig.8 Diagram on the fitting relation on dynamic modulus of elasticity of rocks from M20001 well

\section{Conclusions}

The following conclusions are obtained from the analysis on experimental testing on 80 rock samples from 20 groups (80 samples) of Baikouquan and lower Wuerhe Formation in M2 well area.

(1) In general, there is a good correlation between P\& $S$ velocity of rock samples with poor correlation for M20008 well than that for M2000 well. The fitting relation between $\mathrm{P} \& \mathrm{~S}$ wave velocity in pay zone is: $\mathrm{Vs}=0.3692 \mathrm{Vp}+851.3$.

(2) The dynamic modulus of elasticity dynamic and Poisson's ratio of rocks from Baikouquan Formation are respectively 23152 42242MPa (mean $32146 \mathrm{MPa}$ ) and $0.077 \sim 0.318$ (mean 0.2055), while the dynamic modulus of elasticity dynamic and Poisson's ratio of rocks from 
lower Wuerhe Formation are 12728 42562MPa (mean28401MPa) and 0.095 0.357 (mean0.2425)

(3) The test on the sand conglomerate in M2 well area under the triaxial condition is generally characterized by good brittleness. The static modulus of elasticity and Poisson's ratio of rocks from Baikouquan Formation are respectively $7885 \sim 16770 \mathrm{MPa}$ (average $13745 \mathrm{MPa}$ ) and $0.193 \sim 0.443$ (average 0.2858 ), and while that from low Wuerhe Formation are 8601 21042MPa (average 14884MPa) and 0.111 0.396 (average 0.2565) respectively.

(4) The correlation between dynamic and static mechanical parameters of the sand conglomerate in M2 well area is not generally high, which may be related to the content and distribution of the sand conglomerate.

\section{Acknowledgment}

This article is sponsored by the National Science and Technology Major Project of tight oil\& gas 2016ZX05046

\section{References}

1. Wu Hu. A high yield oil flow was achieved after post-frac evaluation by Xinjiang Oil Co. Xinjiang Petroleum Science and Technology, 2017, 27(1):12.

2. Wang Haitao: Research on optimum fast drilling technology for circum-mahu depression of Xinjiang [D]. Yangtze University, 2016

3. Chen Mian.Review of study on rock mechanics at great depth and its applications to petroleum engineering of china $[\mathrm{J}]$. Chinese Journal of Rock Mechanics and engineering, 2004, 23 (14):2455-2462.

4. SHI Ge,YANG Dongquan.The regression analysis study on velocity and porosity and clay content of rocks[J]. Acta Scientiarum Naturalium Universitatis Pekinensis, 2001, 37(3), 379-384

5. National standards of P.R.C. GB/T50266-2013 《Standard for test method of engineering rock masses》

6. Chen Mian, Jin Yan, Zhang Guangqing. Petroleum Engineering Rock Mechanics [M]. BeiJing: Petroleum Industry Press, 2011.

7. Lou Yishan, Jin Yequan.Rock mechanics and petroleum engineering $[\mathrm{M}]$. BeiJing: Petroleum Industry Press, 2006.

8. Lu Baoping, Bao Hongzhi. Advances in calculation methods for rock mechanics parameters [J]. Petroleum Drilling Techniques, 2005, 33 (5):44-47.

9. Murphy W, Reischer A, Hsu K. Modulus decomposition of compressional and shear velocities in sand bodies [J]. Geophysics, 1993, 58 (2): 227-239.

10. Gui Rong, WAN Yong-ping. Rock mechanics parameters calculation based on conventional logging data: a case study of upper Paleozoic in ordos basin [J]. Journal of Geomechanics, 2012,
18(4):418-424.

11. Hao Jialiang, Qin Guangsheng, Cai Qixin. Experimental investigation of acoustic and elastic mechanics parameters characteristics on rocks in Dongpu depression [J]. Journal of Oil and Gas Technology, 2012, 34(2) 57-61

12. Lin Yingsong, Ge Hongkui,Wang Shunchang. Testing study on dynamic and static elastic parameters of rocks [J].Chinese Journal of Rock Mechanics and Engneering, 1998, 17(2), 216 222

13. Han Laiju, Li Zukui, Yan Jing, et al.Test and application of sonic properties of carbonate rock[J].Chinese Journal of Rock Mechanics and Engneering, 2004, 23(14), 2443-2447

14. Zhou Wen, Gao YaQin, ShanYuming, et al. Rock mechanics properties of tight sandstone reservoir in the $2^{\text {nd }}$ member of Xujiahe formation in Xinchang gasfield, Western Sichuang [J]. Natural Gas Industry, 2008, 28(2):34-37+4.

15. Wang Qian, Ji Shaocheng, Sun Shengsi, et al. Correlations between compressional and shear wave velocities and corresponding Poisson's ratios for some common rocks and sulfide ores [J]. Tectonophysics, 2009, 469 (1): 61-72. 